\title{
Racial Stereotype and African American Resistance Against the Authority in Straight Outta Compton (2015) by Felix Gary Gray
}

\author{
D Agustinus $^{1 *}$ and Risa Rumetha Simanjuntak ${ }^{2}$ \\ 1,2English Department, Faculty of Humanities, Bina Nusantara University, Jakarta, Indonesia \\ *Corresponding author email: risaretha@gmail.com
}

\begin{abstract}
Racial discrimination and stereotyping are major social issues that create sense of difference towards a person or groups of people. This research will be analyzing about racial discrimination, stereotyping, and resistance that are portrayed in the movie Straight Outta Compton directed by Felix Gary Gray by using qualitative method. In addition, Racial Discrimination, Stereotyping, and resistance are to be guided with the theory of post-colonialism. From the movie, the writer aims to show how racial discrimination, stereotyping, and resistance that are portrayed in the movie. Further data also showed labelling and offensive naming towards the group of African-American characters in the movie.In conclusion, it was shown that despite the apparent discrimination, resistance was done without violence and was expressed through music and culture.
\end{abstract}

Keywords: Racial Stereotype, African American Resistance, Straight Outta Compton

\section{INTRODUCTION}

Discrimination is being defined as a treatment of difference for individuals, based upon their membership in a particular group[1]. Which means that discrimination is an act of treatment from one person to another person based upon their characterization in a particular group. With discrimination it brings an issue that discrimination is major social issues that are still occurring almost every countries in the world. From the definition above it is clear that discrimination occurs in many ways because discrimination focuses upon the characteristic of a person in a certain group. Characteristic means that features that a person have such as religion, culture, and race. But in this research, the writer will be focusing upon racial discrimination which focus upon the discrimination that are based upon race.

Stereotyping is being defined as the act of assumption towards people[2]. Which means that stereotyping is the action of a person that assume other people without any investigation or knowledge of the person. Stereotyping is differing with stereotype; stereotyping is the action of a person to assume another person. On the other hand, stereotype is the common type of a person that have been classified. With the issue of stereotyping, stereotyping is also included as a major social issue where people assume other people without any knowledge of the person. The action of stereotyping can lead people into a judgmental person which is considered to be a social issue on a lot of people until today.

The movie is entitled Straight Outta Compton, which title sounds resistance. The resistance can be identified by the meaning of the phrase "straight outta Compton" which indicates the perspective of Compton and the street life of Compton. In addition, very first line in the movie which is "You're about to witness the strength of street knowledge" indicating the street life of Compton. In common definition of resistance, the resistance are commonly portrayed as a demonstration or a riot but in this movie, the resistance that are portrayed are by using rap music, to be precise gangster rap. Rap music is considered to be one of the five elements of hip-hop culture [3]. Differing from the mainstream rapping, gangster rap put detail upon the resistance by preaching upon the unemployment, miseducation, discrimination, homicides, gang life, class oppression and police brutality that dominating the African Americans [3].

Post-colonialism theory is suiTABLE to be use for the movie Straight Outta Compton which is the main material for this research because Straight Outta Compton is a movie that portrayed California Compton in 1988-1995, where racism and police brutality towards African American people are still a common action in Compton. In Compton, where the African American authority is second class compared to the whites. In the movie, Five AfricanAmericans brave enough to resist from the suffering that they are receiving, they were called N.W.A. 
(Niggaz Wit Attitudes) where they rebelled through rapping, in specific gangster rap. Straight Outta Compton is a movie that was released in 2015 and was directed by Felix Gary Gray, the screenplay by Jonathan Herman and Andrea Berloff, and the story by S. Leigh Savidge and Alan Wenkus. The director, Felix Gary Gray, is an American film director, film producer, music video producer, and an actor. Felix Gary Gray has directed several movies such as Friday, The Negotiator, The Italian Job, and Straight Outta Compton.

The movie Straight Outta Compton is a movie that are based on the rap group called N. W. A. The story take place in 1986 until 1995, from how the group was created until the death of one of the characters named Eazy-E. The story focuses upon five African-American individuals that form a rap group called N. W. A. that came from the bitter street of Compton where a lot of police harassment and discrimination occurs. The group form the rap group to perform some form of resistance towards the authority through rap music where the group express their feelings from all of the experienced that they received in the street as an African-American.

The reason this movie is taken to be analyse because the story was based on real life event and tell the struggle of the African American upon the oppressive authority and also to know the elements of post-colonialism are represented in Straight Outta Compton, how the racial discrimination, stereotype, and the resistance that are portrayed in Straight Outta Compton.

In this research there are two questions, which needed to be answered through this research. These problem formulations are: 1. How racial discrimination and stereotyping are portrayed in the movie? 2. How the resistance and the effects of the resistance towards the characters are portrayed in the movie?

\section{PREVIOUS STUDIES}

The theory that is going to be the major theory to this thesis is post-colonialism. Post-colonialism is being define as a connection with the cultures and society after the effect of colonialization[4]. Which means that post-colonialism theory is focusing upon the effect of the culture and society after the colonial rule. The issues of resistance and racism will be the major discussion in the paper and also to notify the readers that racism is a cruel act where people were discriminated because of physical appearance and race

Previous research had shown discrimination and stereotyping resulted innegative impacts. The racial discrimination towards African-American family, for instance, resulted in the family experience "othering". Othering generally means strange and unwanted. The "other" in the previous study was the result of post-colonial influence [5]. Another study.

In Januarius's thesis, his problem formulations consist of identifying the character, settings, and symbolism in the movie, identified the postcolonial issues such as racial discrimination, racial segregation, and stereotype that are represented in the movie, identify the process of hybridity and the concept of mimicry in the movie. To Januarius's thesis, the writer research have some similarity to Januarius's thesis, both the writer and Januarius analyze the characters, the racial discrimination. But again there are difference between the writer and Januarius's research is that mine more focusing upon the resistance and Januari's research focus upon the hybridity and the concept of mimicry.

Another study depicted the relationship of power and tone of hegemony in the American rhetoric. The study revealed the different strategies in the political speeches of Obama during his presidency. Study of his speeches had been conducted through investigating the language aspects, the practice of discourse, and the discursive order used. It was found that there were three formations used that open segments, content segments, and closing segments.

\section{RESEARCH METHODS}

This research uses qualitative approach and literary analysis method. The reason for this research using qualitative approach is that the research is analysing about the behaviour upon racial stereotype and the resistance that are occurring after colonialism in that literature work which can also be called postcolonialism, through qualitative approach the writer is going to analyse the literature work subjectively which can only be done with the qualitative approach. Other reason is that the writer will have to be able to analyse the research by understanding both characters and actions that are occurring in the literature work. Aside from the reason in qualitative reasons, the literary analysis is also as important as the qualitative approach. The reason is that in literary analysis method, the method let the writer focusing upon the materials the writer uses, with that method the writer can subjectively interpret the literature work that are occurring in the literature works but also are connected to the goal of the research.

The steps of conducting this research is seen in Fig.1: 


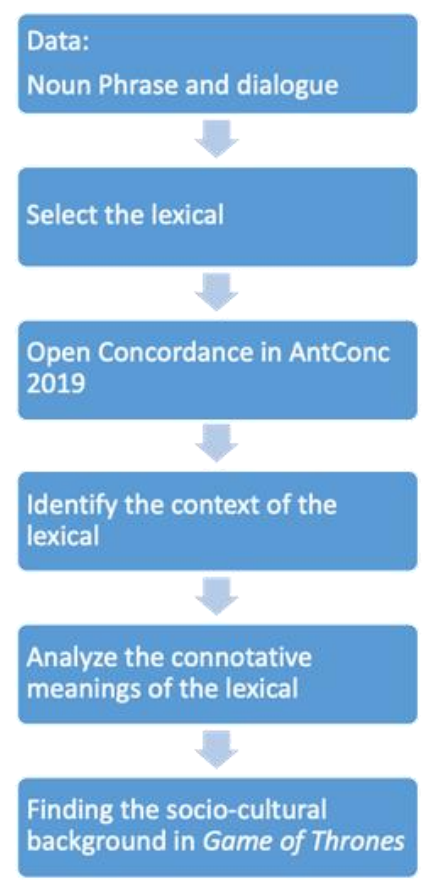

FIGURE 1. Research procedure

\section{RESULTS AND DISCUSSION}

\subsection{The intrinsic aspects: the element of fictions}

From the previous chapter in the theoretical framework, element of fiction in detail have been explain in that chapter. To summarize, element of fiction is the elements that are used in the literary work or fiction. In this chapter, the elements that are going to be discussed in this chapter are character and characterization and settings. Which are the necessary elements that can provide a clear result of the analysis.

\subsection{The characters and characterization}

There are five main characters that are in the movie Straight Outta Compton and these five characters are the characters that will be use in the analysis of this movie.Eric Wright (also known as Eazy-E) is a regular African-American citizen that live in Compton. Before he was known as a rapper in rap group called N.W.A (Niggaz With Attitude), he was a successful drug dealer in Compton. Eazy-E is one of the main characters in the movie. He was a drug dealer at first then later on develop into a rapper that may be considered to be a legend in the Black Community. From the movie, viewer can identify Eazy-E as a strong, brave, and a creative entrepreneur. From the beginning scene of the movie that introduce Eazy-E, the viewer can see that Eazy$\mathrm{E}$ is a strong and brave character. In the movie, the characterization for Eazy-E is unique because the characterization that Eazy-E has is different compare the other members of the group. Eazy-E characterization can be identified as the manager Jerry Heller. The reason of Jerry Heller is the characterization of Eazy-E because the manager Jerry Heller is the one that in charge of the financial of the group, which indicate the passion of entrepreneur of Eazy-E. Also, Eazy-E's characterization indicates that the group financial progression.

Andre Young also known as Dr. Dre is a common African-American citizen that live in Compton. Dr. Dre before he joins the rap group N.W.A. he was a regular DJ that work at a night club with a very stingy manager which means that he didn't make enough money to support his family enough. Dr. Dre is also one of the main characters in the movie Straight Outta Compton. Dr. Dre is a kind and very talented character. Most of the songs that were created in the group N.W.A. mainly composed by Dr. Dre. Through the movie the audience can see that he is a very talented person especially creating music. There are numerous scene that shows Dr. Dre is composing. Dr. Dre characterization is the musical composing tools and records. Most of the time that Dr. Dre are in the movie, he is composing "beats" (which also can be known as music) where he then can release it into a song. Because Dr. Dre is the composer most of the songs that the group creates.

O'Shea Jackson also known as Ice Cube is a young ordinary African-American that also live in Compton. Before he join the rap group N.W.A. Ice Cube is just a high school student that are really talented at writing lyrics. Ice Cube is one of the main 
characters in this movie. Ice Cube is a hot headed but strong character in this movie. With his talent as a lyric writer he is soon become one of the members of the rap group N.W.A. as one of the writer and rapper. Most of the songs that were produced by N.W.A. are mostly written by Ice Cube. One of the most popular song that Ice Cube wrote was "Fuck The Police". From the creation of that song, it indicating that Ice Cube is a strong character that refuse to be quite towards something negative towards him. Ice Cube characterization is paper and pen. The reason why Ice Cube characterization is paper and pen because Ice Cube is a song writer where he mostly write his lyrics and for the other members lyrics which Ice Cube specialty.

Antoine Carraby also known as DJ Yella is also the member of the rap group N.W.A. mostly producing the music as a DJ for the group. DJ Yella in this movie mostly assisting Dr. Dre in composing and creating music for the group. But DJ Yella is also one of the main character of this movie. DJ Yella is differ from other character because he is the jester of the movie which mostly used for comedic situation for the movie. DJ Yella characterization is his perverted minds towards women. There were jokes and scenes in the movie that related to DJ Yella, mostly related to perverted stuff for example is adult films.

Lorenzo Patterson also known as MC Ren is also one of the rappers in the rap group N.W.A. MC Ren also write some songs that were produced by the N.W.A. But not as much as Ice Cube. MC Ren really focused more with the rapping rather than writing hence the name MC Ren. MC Ren is one of the five main characters that are in the movie. MC Ren is a quite but also strong person but also very mysterious. In the movie, if MC Ren I being compared to the other characters, MC Ren is more likely the one who is speak when it is necessary. Which also indicates the mysteriousness of the character.MC Ren characterization is a microphone. The reason $\mathrm{MC}$ Ren characterization is a microphone is that. Compare to the other members his rhythm is the most on point which indicates his specialty in the group is rapping or singing.

\subsection{Settings}

In this section, the writer will be identifying the settings that occurs in the movie. Namely, Place and Time. The movie Straight Outta Compton happened through multiple settings which is going to be identified by the writer.

First of all, in the movie Straight Outta Compton there are a lot of settings that purposely shown in the movie by showing mostly the place but some of the settings that were shown in the movie also shown the time and the event of the settings. All of settings can be seen in the TABLE below where it is divided into three columns which is Place, Time, and Event.

TABLE 1. Settings

\begin{tabular}{|c|c|c|}
\hline Place & Time & Event \\
\hline Compton, CA & 1986 & - \\
\hline $\begin{array}{c}\text { Doo-To's Club, Compton } \\
\text { CA }\end{array}$ & - & - \\
\hline Skateland & 1988 & - \\
\hline Torrence, $\mathrm{CA}$ & - & $\begin{array}{c}\text { Album Straight Outta Compton } \\
\text { - recording session }\end{array}$ \\
\hline Crenshaw, Blvd & - & - \\
\hline $\begin{array}{l}\text { The Summit, Houston, } \\
\text { Texas }\end{array}$ & - & Tour concert performance \\
\hline $\begin{array}{l}\text { The Spectrum, } \\
\text { Philadelphia, PA }\end{array}$ & - & Tour concert performance \\
\hline $\begin{array}{c}\text { Joe Louis Arena, Detroit, } \\
\text { MI }\end{array}$ & - & Tour concert performance \\
\hline Los Angeles, CA & - & - \\
\hline Priority Record & 1990 & - \\
\hline $\begin{array}{c}\text { Green Street Studio, New } \\
\text { York City }\end{array}$ & - & Ice-Cube solo recording session \\
\hline Eazy-E's House & - & Wet \& Wild Party \\
\hline New Music Seminar & - & - \\
\hline Death Row Records & 1991 & - \\
\hline
\end{tabular}

One of the most important settings in the movie Straight Outta Compton, from the title itself the movie takes place in California Compton. Which is portrayed in the movie to be in 1986 . 
The portrayal of the neighbourhood Compton in the movie, are portrayed very clearly with the culture of African-American Community, especially towards the culture of the settings. The portrayal of the 1986 Comptonshows the typical neighbourhood of Compton to create a sensation towards the viewer of what it feels like to be living in Compton in 1986.

To explain more detailed towards the setting of Compton in 1986. The writer is going to provide some pictures to support the writer's statement in the previous paragraph. First of all, the culture that are in Compton in 1986. The urban culture that can be seen throughout 1986 Compton in the movie are drugs, gangs, and prejudice of police action towards African-American people in Compton.

Police misused of the authority towards AfricanAmerican which leads to police prejudice towards the African-American has become a common thing in Compton. Police raids comes out of nowhere and arrest as many African-American who they assume suspicious. This example can be explained more.

The other supporting detail of post-colonialism is resistance. Resistance is an act of rebellious where one person or a group of people resist a certain ruling of discomfort to the person or the group. For further explanation of resistance can be seen in chapter 2 where the explanation of resistance is more detailed. Resistance occurs in Straight Outta Compton in a different way than regular resistance but there is also some common resistance. For example, the resistance through speaking. The unique part of the movie Straight Outta Compton's resistance is that the characters resist through music. To be more precise through rapping. Resistance through rapping, they have their own name for it which is gangster rap. For explanation of resistance through music and gangster rap.

Resistance have a different perspective with racial discrimination and stereotyping. Where racial discrimination and stereotyping are the action that degraded the minority. Resistance are more towards the fighting back of the minority towards the majority or the resistance of the effects of postcolonialism. With the resistance of the effect of postcolonialism, resistance then can be considered to be within the post-colonialism but can be categorized as the "anti" post-colonialism.

The example of resistance is the opening sentence, "You're about to witness the strength of street knowledge". The sentence have some indication of resistance which means that the viewer are going to witness the real strength of street knowledge which indicating that people are underestimating the knowledge of the streets which in the movie, they are going to show the viewer how powerful it is to have street knowledge. The reason why this sentence are included as a resistance is that, in the group perspective people have underestimated the knowledge of the street which according to the group street knowledge is powerful to have which makes the group resist towards the ideal of underestimating the street knowledge.

\section{CONCLUSION}

The analysis from previous chapter has successfully answered all the research questions. The first question "How racial discrimination and stereotyping are portrayed in the movie?" has been answered, showing that there is racial discrimination towards the characters and stereotyping towards the characters.Stereotyping is also shown to be apparent in the movie. The stereotyping portrayed in the movie is shown clearly by several scenes, involving police raids without any reason.

The second question, "How the resistance and the effects of the resistance towards the characters are portrayed in the movie?" has also been answered. There are two types of resistance portrayed in the movie. First, there iss direct resistance such as directly resisting of arrest and command by the police. Second, there is indirect resistance towards discrimination, such as creating song lyrics with satire towardsdiscrimination. The effect of the resistance towards the characters are also portrayed in the movie.

In conclusion, the movie has revealed AfricanAmerican awareness of the ongoing discrimination. However, it has been stated that resistance would take place in peaceful manner, following the rise of the young people's voice against discrimination.

\section{REFERENCES}

[1] J. 2010. Bodenhausen, G. \& Richeson, Prejudice, stereotyping, and discrimination. In R. Baumeister \& E. Finkel, Advanced social psychology, the state of the science pp. 341-383. Oxford: Oxford University Press. .

[2] L. 2013. Parvis, Understanding Cultural Diversity in Today's Complex World. Lexington: An Embrace Publications Book.

[3] \& Q. F. 2010 Devos T, Gavin K, Say "Adios" to the American Dream? The interplay between ethnic and national identity among Latino and Caucasian Americans, Cultural Diversity and Ethnic Minority Psychology, 16, pp. 37-49. .

[4] Y. G. 2017. Pertiwi, The many colors children see: development and intervention of children's social prejudice, Buletin Psikologi, 25(1), 1-10.

[5] T. 2009 Kochman, Rapping in the black ghetto. Society, 6(4), 26-34. 